\title{
Fluorometric determination of free and total isocitrate in bovine milk
}

\section{Torben Larsen ${ }^{1}$}

Department. of Animal Science, Aarhus University Blichers Allé 20, PO Box 50, 8830 Tjele, Denmark

\begin{abstract}
Isocitrate is an intermediate metabolite in the citric acid cycle found both inside the mitochondria as well as outside in the cytosolic shunt. Oxidation of isocitrate is believed to deliver large fractions of energy [i.e., reducing equivalents (NADPH) in the bovine udder] used for fatty acid and cholesterol synthesis. This study describes a new analytical method for determination of free and total isocitrate in bovine milk where timeconsuming pretreatment of the sample is not necessary. Methods for estimation of both total isocitrate and free isocitrate are described, the difference being the esterified or even lactonized isocitrate. On average, $20 \%$ (6-27\%) of cow milk isocitrate was esterified and free isocitrate correlated significantly with total isocitrate $(\mathrm{r}=0.98)$. The present fluorometric determination correlated well with the traditional spectrophotometric determination of isocitrate. Milk samples from Danish Holstein cows (984) contained significantly less isocitrate than milk from Danish Jersey cows (760; i.e., 0.134 vs. $0.211 \mathrm{mmol} / \mathrm{L}$ ). Isocitrate in milk is correlated to milk protein, fat, and citrate, and it is speculated, based on biochemistry, former studies, and the present, that isocitrate may reflect the energy situation in the mammary gland. The use of isocitrate as a biomarker of the energy status in the dairy cow is warranted.
\end{abstract}

Key words: esterified isocitrate, milk, fluorometry, biomarker, energy status

\section{INTRODUCTION}

Isocitric acid is widespread in living material (e.g., bacteria, plant, and animal tissues). The formation of isocitrate is, in mammalian metabolism, closely connected to citric acid, which in turn is an important intermediate in energy metabolism. Isocitrate is oxidized by the enzyme isocitrate dehydrogenase (ICDH), where carbon dioxide is liberated and 2-oxoglutarate is the oxidized product. Three main groups of ICDH are known: (1) $\mathrm{NAD}^{+}$-dependent (EC 1.1.1.41), abundant

Received February 5, 2014.

Accepted August 17, 2014.

${ }^{1}$ Corresponding author: Torben.Larsen@agrsci.dk inside the mitochondria and an important regulatory region of the citrate cycle (TCA cycle); (2) $\mathrm{NADP}^{+}$dependent form, also inside the mitochondria (EC 1.1.1.42, 2), and (3) $\mathrm{NADP}^{+}$-dependent form in the cytosol (EC 1.1.1.42, 1). However, both citrate and isocitrate are able to cross the mitochondrial membrane, alleviating intra- and intermitochondrial exchange of energy precursors.

Lipogenesis in the ruminant is very different from lipogenesis in nonruminant animals, both considering precursors for the FA and considering the origin of energy supply. In ruminants, about one half of the milk FA (molar percent) are derived from de novo synthesis (Bauman and Griinari, 2003). $\beta$-Hydroxybutyrate and acetic acid are important precursors in ruminant lipogenesis. Fatty acid synthesis is an energy-demanding series of reductive steps using reducing equivalents in the form of NADPH, namely $2 \mathrm{~mol}$ per $2 \mathrm{C}$-incorporation. A significant part of the NADPH-production in ruminant mammary glands is believed to be oxidative decarboxylation of isocitrate (Bauman et al., 1970; Gumaa et al. 1973; Chaiyabutr et al., 1980). The latter process is mediated by extra mitochondrial ICDH (EC 1.1.1.42; 1), also believed to be the main energy source for synthesis of cholesterol (Moore and Christie, 1979). Cytosolic $\mathrm{NADP}^{+}$-dependent ICDH activity is therefore abundant in ruminant mammary cells (Bauman et al. 1970; Gumaa et al. 1973).

Some attention has been given to isocitrate and ICDH activity in ruminant mammary gland and milk to describe the physiological status of the animal or the production conditions. Most of these observations support the important role of citrate-isocitrate-2-oxoglutarate in the milk energy turnover.

Measurements of isocitrate in milk have so far all been based on spectrophotometry, which is not an ideal method considering the opaque protein and fat matrix. Analyses are performed after a pretreatment of the sample (i.e., centrifugation to separate the fat), followed by precipitation of protein with perchloric acid $\left(\mathrm{HClO}_{4}\right)$ to obtain a clear fraction and subsequent neutralization (Faulkner, 1980; Faulkner and Clapperton, 1981; Chaiyabutr et al., 1981; Faulkner et al., 1986).

The present analytical method for determination of isocitrate is principally based on the spectrophotometric 
(UV) method (Beutler, 1989); however, the produced $\mathrm{NADPH}$ is subsequently used in a second reaction for reduction of the nonfluorescent precursor resazurin to produce the fluorescent substance resorufin, which is detected by fluorometry. The present fluorometric technique renders pre-treatment of the sample superfluous. It is well recognized from food analyses that a certain fraction of the isocitrate may be esterified or lactonized (internal esterification; Boehringer Mannheim, 1995). We have used this obtained knowledge to distinguish between free and total isocitrate by the fluorometric method.

\section{MATERIALS AND METHODS}

\section{Samples and Standard Analyses}

Milk samples $(\mathrm{n}=1,744)$ were from the resident herd at the Danish Cattle Research Centre (Tjele, Denmark). Analyzed samples were used to investigate the correlation among free isocitrate, selected milking data, other milk components, and udder health as indicated by milk SCC. The milking system is a robotic system, where representative milk samples are taken in a 10-mL tube, predosed with the preservative Bronopol (Myacide, Pharma BP, BSF Ltd., Nottingham, UK) to obtain a $100-\mathrm{mg} / \mathrm{kg}$ sample. The samples were stored at $4^{\circ} \mathrm{C}$ and brought to the laboratory every morning. Milk citrate, lactose, fat, and protein were determined by infrared spectroscopy (CombiFoss 4000, Foss Electric Ltd., Hillerød, Denmark). Determination of SCC was performed at a commercial laboratory (Eurofins, Holstebro, Denmark) using standard Fossomatic cell counter (EN ISO 13366-3; Foss Electric Ltd.).

Intrinsic milk enzymes were inactivated (denatured) by heating the milk samples in a water bath. Isocitrate in milk is found in a free state and in an esterified state. Samples analyzed for free isocitrate were heat-treated at $75^{\circ} \mathrm{C}$ for $10 \mathrm{~min}$. Samples analyzed for total isocitrate were adjusted to $\mathrm{pH} 10$ with $1 \mathrm{~mol} / \mathrm{L}$ of $\mathrm{NaOH}$ and heat-treated at $96^{\circ} \mathrm{C}$ for $20 \mathrm{~min}$, because heat and the alkaline environment breaks the chemical ester bond between lactate and other intrinsic components. Thus, total isocitrate is the sum of free isocitrate and esterified isocitrate.

\section{Isocitrate Analysis}

Two reagents were necessary for the detection of isocitrate by fluorometry. Reagent 1 contained the enzyme that mediates the conversion of isocitrate to 2-oxoglutarate (i.e., ICDH; EC 1.1.1.42), Tris-buffer, $\mathrm{pH} 7.2$, $\mathrm{NADP}^{+}$, and Mn-ions that activates the enzyme. Reagent 2 contained the necessary fluophore, resazurin, and the enzyme mediating the reduction of resazurin, diaphorase (EC 1.6.99.1), both dissolved in Tris-buffer with Triton X-100 (Merck, Darmstadt, Germany).

Eighty microliters of diluted sample (1:2 water) was pipetted into a microplate, then $60 \mu \mathrm{L}$ of reagent 1 was added $(t=0)$ and the mixture was incubated 3 min (incubation 1) at room temperature. After this, $40 \mu \mathrm{L}$ of reagent 2 was added and the plate was incubated for an additional $6 \mathrm{~min}$ (incubation 2) and read (excitation: $544 \mathrm{~nm}$; emission: $590 \mathrm{~nm}$ ) in a fluorometer (FluoStar Galaxy, BMG Labtechnology, Germany). Incubation conditions for incubation 1 were: sample fraction = 0.19 ; isocitrate maximum $=0.076 \mathrm{mmol} / \mathrm{L} ; \mathrm{Mn}^{++}=$ $0.77 \mathrm{mmol} / \mathrm{L}$; Tris-buffer $(\mathrm{pH} 7.2)=31 \mathrm{mmol} / \mathrm{L} ; \mathrm{ICDH}$ activity $=0.11 \mathrm{U} / \mathrm{mL} ; \beta-\mathrm{NADP}^{+}=0.123 \mathrm{mmol} / \mathrm{L}$. Incubation 2 conditions were: diaphorase activity $=$ $2.2 \mathrm{U} / \mathrm{L}$; resazurin $=0.28 \mathrm{mmol} / \mathrm{L}$; Triton $\mathrm{X}-100=$ $0.0024 \%$; Tris-buffer $=34 \mathrm{mmol} / \mathrm{L}$.

\section{Analytical Details}

The ICDH oxidizes isocitrate to 2-oxo-glutarate, whereas $\mathrm{NADP}^{+}$is reduced equivalently to NADPH + $\mathrm{H}^{+}$at $\mathrm{pH}$ 7.2. The reaction is activated by $\mathrm{Mn}$ ions. The developed NADPH $+\mathrm{H}^{+}$equivalently reduced resazurin to resorufin, mediated by the enzyme diaphorase; the amount of resorufin is detected by fluorometry and compared with a standard curve. All dilutions and additions of reactants were performed in a laboratory robotic system (Biomek 2000; Beckman Coulter, Pasadena, CA).

\section{Standards and Controls}

Standards were prepared in isocitrate-free milk: 45 $\mathrm{mL}$ of milk were supplied with $5 \mathrm{~mL}$ of $1 \mathrm{~mol} / \mathrm{L}$ Trisbuffer, $\mathrm{pH} 7.2,25 \mathrm{mg}$ of Mn-sulfate, $14 \mathrm{U}$ of ICDH, and $10 \mathrm{mg}$ of $\mathrm{NADP}^{+}$and incubated for $60 \mathrm{~min}$ at $40^{\circ} \mathrm{C}$. Terminally, $1.0 \mathrm{~mL}$ of hydrogen peroxide $(15 \%)$ was added, mixed immediately, and the mixture was heat-treated at $75^{\circ} \mathrm{C}$ for $10 \mathrm{~min}$. Standards were prepared by addition of DL-isocitrate (Acros 205010010, MW 258.07; Acros Organics, Geel, Belgium) to the isocitrate-free milk; concentrations of standards were $0,0.02,0.04,0.08,0.100 .20,0.30$, and $0.40 \mathrm{mmol} / \mathrm{L}$ of D-isocitrate. Control samples were produced likewise, using 0.069 and $0.227 \mathrm{mmol} / \mathrm{L}$ of D-isocitrate. Standards and controls were measured in duplicate on every microplate.

\section{Verification of the Assay}

Four hundred thirty milk samples were analyzed for both total isocitrate and free isocitrate according to 


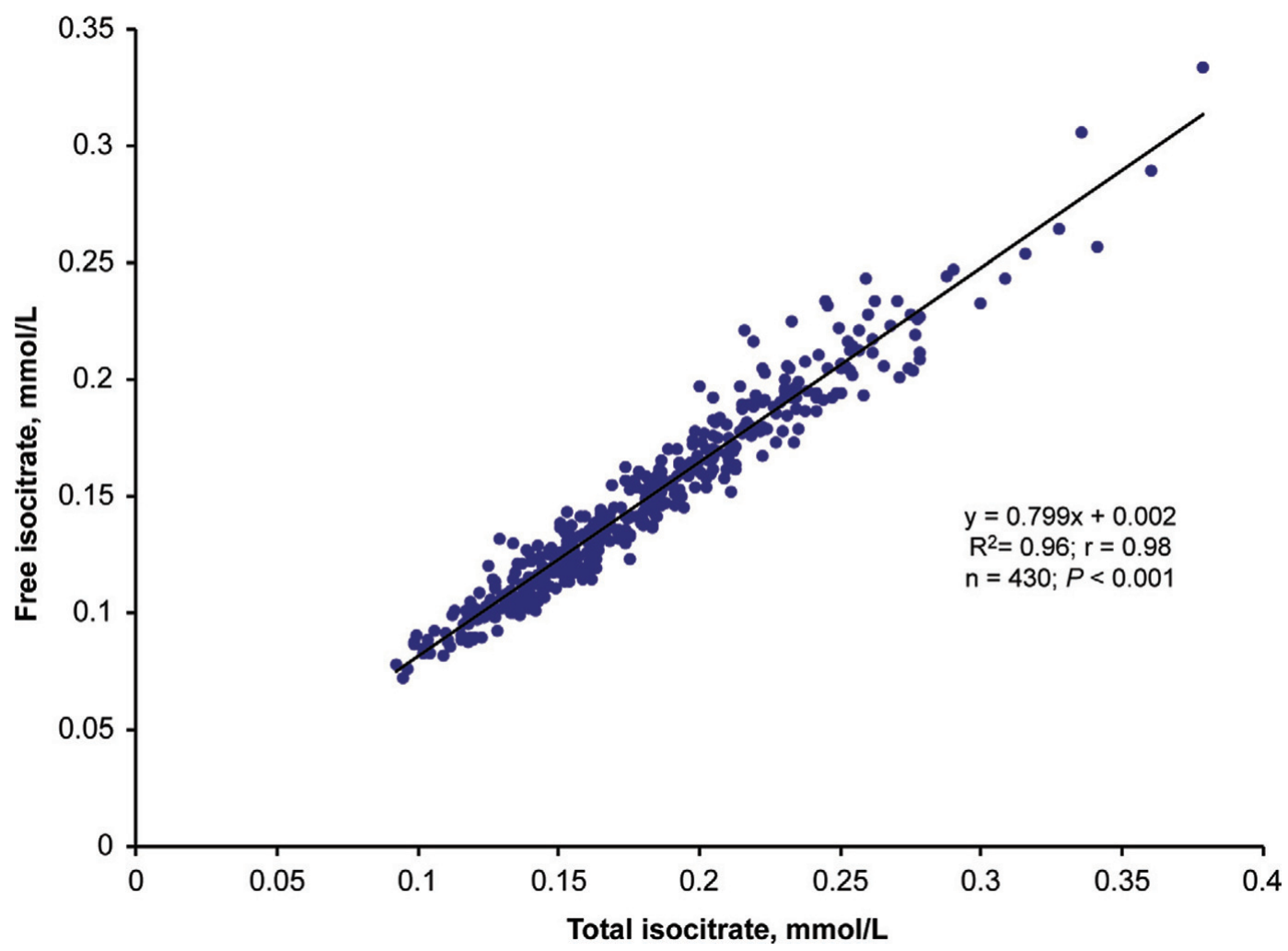

Figure 1. Four hundred thirty random milk samples were analyzed for total isocitrate (abscissa) and free isocitrate (ordinate) according to the procedures described herein. Color version available in the online PDF.

the scheduled procedure to elucidate the circumstances about the ratio of the 2 forms. The present fluorometric analyses of isocitrate were validated by means of several initiatives comprising reference measurements by fluorometry and spectrophotometry on precipitated milk samples, investigation of the linearity of the method, and checking the accuracy and the precision.

Reference measurements by fluorometry were completed by using 40 milk samples in analysis for free and total isocitrate by the presented fluorometric assay (3 replicates). Concurrently, parallel milk samples were precipitated with $3 \%$ metaphosphate or $12 \%$ perchloric acid ( $0.5 \mathrm{~mL}$ of acid to $2.0 \mathrm{~mL}$ of milk), centrifuged at room temperature, $2,000 \times g$, for $10 \mathrm{~min}$, and the supernatant subsequently neutralized with 2 $\mathrm{mol} / \mathrm{L}$ of potassium carbonate. The neutralized (clear) supernatants were analyzed by fluorometry compared with standards treated likewise (metaphosphate- and perchloric acid-treated, respectively). Furthermore, samples precipated by perchloric acid were analyzed for isocitrate by spectrophotometry (Advia $1650 \mathrm{Au}-$ toanalyzer, Siemens Diagnostics; Siemens Medical Solutions, Tarrytown, NY). The analytical conditions were: sample fraction $=0.083 ; \mathrm{Mn}^{++}=0.62 \mathrm{mmol} / \mathrm{L}$;
Tris-buffer $(\mathrm{pH} 7.2)=62 \mathrm{mmol} / \mathrm{L} ; \mathrm{ICDH}=0.22 \mathrm{U} /$ $\mathrm{mL} ; \beta-\mathrm{NADP}^{+}=0.148 \mathrm{mmol} / \mathrm{L}$.

Linearity of the fluorometric assay was checked by spiking milk samples with pure isocitrate. One hundred forty-four samples were spiked with $0.08,0.09,0.10$, $0.16,0.18$, or $0.20 \mathrm{mmol} / \mathrm{L}$ of isocitrate, respectively. Linearity of the assay was also investigated by merging samples of known isocitrate content; 1 low sample was mixed with 1 high sample, then (1) 48 samples were analyzed for total isocitrate and (2) 96 samples were tested for free isocitrate. The expected isocitrate concentration was subsequently compared with the actual measurement.

Intra-assay validation of free isocitrate was conducted on 288 random samples replicated 3 times on the same microplate. Interassay validation and accuracy was assayed on 17 microplates, where low $(0.069 \mathrm{mmol} / \mathrm{L})$ and high control $(0.227 \mathrm{mmol} / \mathrm{L})$ were measured repeatedly. The potential interference of citrate on the present analysis of isocitrate was investigated for both free and total isocitrate, where 16 ordinary, fresh milk samples were spiked with 0,10 , or $20 \mathrm{mmol} / \mathrm{L}$ of citrate ( $\mathrm{pH} 7.2 ; 3$ replicates) and analyzed according to the described procedure. Pearson correlations were used to 
determine the correlation among free and total isocitrate in milk with DIM, milk yield, time since last milking, and components in milk (i.e., fat, protein, lactose, citrate, and SCC). The effect of breed was determined by 2 -sided $t$-test.

\section{RESULTS}

Total isocitrate (i.e., after liberation of the esterified acid) ranged between 0.093 and $0.378 \mathrm{mmol} / \mathrm{L}$ for the analyzed material (mean $0.179 \mathrm{mmol} / \mathrm{L} ; \mathrm{n}=430$ ). Correspondingly, free isocitrate ranged between 0.072 and $0.333 \mathrm{mmol} / \mathrm{L}$ (mean 0.147). The ratio between free and total isocitrate was between 0.729 and $0.939\left(\mathrm{P}_{2}-\right.$ $\mathrm{P}_{98}$ interpercentile, where $\mathrm{P}=$ percentile; mean 0.816). The results are summarized in Figure 1.

Reference measurements by fluorometry and spectrophotometry are shown in Table 1. Fluorometric determination of milk samples precipitated by metaphosphate gave numerically lower values than direct fluorometric determinations of both free isocitrate and total isocitrate. However, whole and precipitated milk were significantly correlated $(P<0.001)$ for both free and total isocitrate. Milk samples precipitated by perchloric acid showed levels of isocitrate comparable to the direct measurements of total isocitrate $(P<0.001)$, both measured by fluorometry and spectrophotometry. Fluorometry of precipitated samples gave on average $\sim 9 \%$ lower values than spectrophotometry. Fluorometry on whole milk samples were $\sim 11 \%$ lower than spectrophotometry on precipitated samples; see Table 1 for details.

The linearity check of the fluorometric isocitrate assays is given in Table 2. Measurement of samples spiked with known concentrations of pure isocitrate gave results similar to the expected. Results from measurements of free isocitrate in merged samples (low + high, 1:1) revealed on average $9 \%$ higher values than expected (0.191 vs. $0.175 \mathrm{mmol} / \mathrm{L})$, whereas total isocitrate measurements gave on average $3 \%$ higher values than expected.

The intra-assay precision varied from 0.12 to $7.0(\mathrm{CV}$, $\mathrm{n}=288$ ), mean CV was 1.8. The interassay precision was for low-control samples $8.6(\mathrm{CV}, \mathrm{n}=17)$, and for high-control samples $5.8(\mathrm{CV}, \mathrm{n}=17)$. The inaccuracy was 0.0004 and $0.0020 \mathrm{mmol} / \mathrm{L}$, respectively, for low $(0.069 \mathrm{mmol} / \mathrm{L})$ and high $(0.227 \mathrm{mmol} / \mathrm{L})$ controls, resulting in a relative bias of 0.6 and $0.9 \%$, respectively.

Samples spiked with $0 \mathrm{mmol} / \mathrm{L}$ of citrate ranged from 0.127 to $0.214 \mathrm{mmol} / \mathrm{L}$ of total isocitrate (mean 0.167 $\mathrm{mmol} / \mathrm{L}$ ). Samples spiked with $10 \mathrm{mmol} / \mathrm{L}$ of citrate were on average $2.8 \%$ higher $(\mathrm{r}=0.987 ; P<0.001)$ and samples spiked with $20 \mathrm{mmol} / \mathrm{L}$ of citrate were on average $0.3 \%$ lower in total isocitrate $(\mathrm{r}=0.938$; 
Table 2. Linearity of the fluorometric isocitrate assay was investigated by spiking of milk samples with known concentrations of isocitrate (A; $0.08 ; 0.09 ; 0.010 ; 0.16 ; 0.18$; or $0.20 \mathrm{mmol} / \mathrm{L}$ ) or by merging $(1: 1)$ milk samples low in isocitrate with milk samples high in isocitrate, and then analyzed for free isocitrate (B) or total isocitrate (C)

\begin{tabular}{|c|c|c|c|c|c|}
\hline Item & Analysis & $\mathrm{n}$ & \multicolumn{2}{|c|}{ Isocitrate $\mathrm{mmol} / \mathrm{L}$, mean (range) } & Equation \\
\hline $\mathrm{A}$ & Spiking of milk samples with isocitrate & 144 & $0.274(0.186-0.444)$ & $0.269(0.188-0.471)$ & $\mathrm{y}=0.98 \mathrm{x}+0.000^{*}$ \\
\hline $\mathrm{C}$ & Total isocitrate & 24 & $0.182(0.109-0.276)$ & $0.177(0.103-0.286)$ & $\mathrm{y}=0.96 \mathrm{x}+0.012^{*}$ \\
\hline
\end{tabular}

$P<0.001)$. Samples spiked with $0 \mathrm{mmol} / \mathrm{L}$ of citrate ranged from 0.102 to $0.166 \mathrm{mmol} / \mathrm{L}$ of free isocitrate (mean $0.133 \mathrm{mmol} / \mathrm{L}$ ). Samples spiked with $10 \mathrm{mmol} / \mathrm{L}$ of citrate were on average $1.8 \%$ higher $(\mathrm{r}=0.961 ; P<$ 0.001 ) and samples spiked with $20 \mathrm{mmol} / \mathrm{L}$ of citrate were on average $2.3 \%$ lower in free isocitrate $(\mathrm{r}=0.982$; $P<0.001)$. Coefficient of variation was in all instances below $6 \%$ for the replicates.

The comparisons between isocitrate and basic milking data and measured standard variables are shown in Table 3. The mean isocitrate content of the samples was $0.168 \mathrm{mmol} / \mathrm{L}\left(\mathrm{P}_{2}-\mathrm{P}_{98}\right.$ interpercentile $\left.=0.070-0.293\right)$. Milk from Danish Holstein cows (984) contained significantly less isocitrate than milk from Danish Jersey cows (760; i.e., 0.134 vs. $0.211 \mathrm{mmol} / \mathrm{L} ; P<0.001$ ). The isocitrate concentration is positively correlated to the fat, protein, and citrate content in milk (Table 3).

\section{DISCUSSION}

Milk may contain indigenous enzymes able to use $\mathrm{NADP}^{+}$as co-factor, thereby producing NADPH + $\mathrm{H}^{+}$and, second, the fluorophore we are detecting in the present setup. Such a parallel production would obviously obstruct the present detection of isocitrate. However, few relevant enzymes are mentioned in the literature (e.g., Farkye, 2003). Malic enzyme (EC 1.1.1.40), 6-phosphoglucuronate dehydrogenase (decarboxylating; EC 1.1.1.44), and glucose-6-phosphate dehydrogenase (EC 1.1.1.49) are listed, and also mentioned by Bauman et al. (1970), Gumaa et al. (1973), and Grigor and Hartman (1985) in relevant studies. However, the activity of these enzymes is measured in mammary gland cytosol, from cow or sheep or in sow or rat milk. Furthermore, the essence of the 2 first articles is explicit that ICDH-activity in the mammary gland cytosol is more than 10 times higher than the other enzymes, especially for ruminants. Therefore, we chose to heat-treat the milk samples $\left(75^{\circ} \mathrm{C}\right.$ for $\left.10 \mathrm{~min}\right)$ to denature all indigenous enzymes (including ICDH) to avoid both unwanted production and oxidation of already-produced NADPH, because both circumstances would interfere with the assessment of isocitrate.

Approximately $20 \%$ of the total isocitrate in milk seems to be esterified to other milk components or even lactonized. We are unsure if the esterified fraction, be-

Table 3. Milk samples were analyzed for standard variables and free isocitrate and correlated (Pearson correlation, r) mutually and to basic milking data ${ }^{1}$

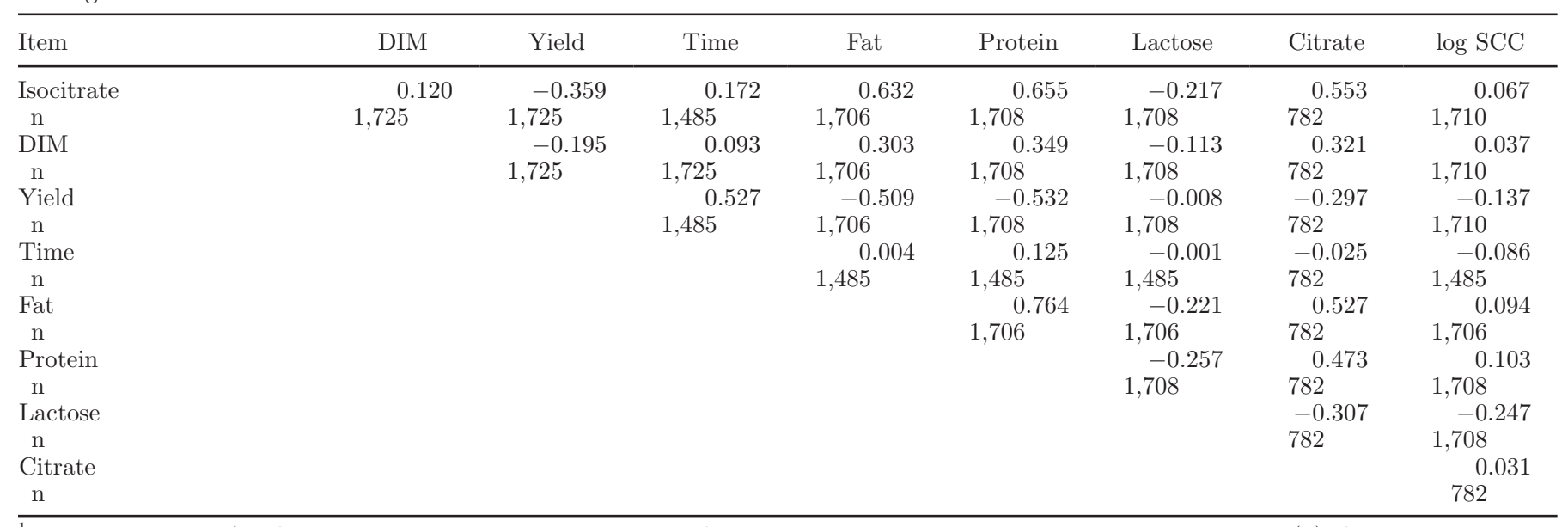

${ }^{1}$ Isocitrate $=\mathrm{mmol} / \mathrm{L}$ of milk; yield $=$ milk yield in kilograms for the actual milking; time = time since last milking $(\mathrm{h})$; fat, protein, lactose, citrate $=\%$ in milk. 
tween 27 and $6 \%\left(\mathrm{P}_{2}-\mathrm{P}_{98}\right.$ inter percentile, $\left.\mathrm{n}=430\right)$ obtained in our study, could be linked to nutritional or physiological conditions in the cow. Literature on this subject is scarce and future experiments and studies will have to elucidate this question.

Addition of citrate to the reaction medium-comparable to the natural content- - did not influence the results of either free or total isocitrate. Citrate is not a substrate for the ICDH enzyme supplied to the assay, and obviously no transformation of citrate to isocitrate occurred in the sample. If milk contains aconitase [i.e., the catalytic step between citrate and isocitrate, as postulated by Faulkner et al. (1986)], then the aconitase activity is most likely destroyed during the initial heat treatment.

The obtained results concerning linearity test, precision, and accuracy are acceptable for analytic as well as descriptive use. Both fluorometric as well as spectrophotometric reference analyses based on perchloric acid precipitations of protein and fat showed results comparable to the present direct measurement of total isocitrate.

All studies and publications until now have used the spectrophotometric analyses on perchloric acidprecipitated samples (e.g., Faulkner, 1980; Chaiyabutr et al., 1981; Hurtaud et al., 1998, 2000; Rigout et al., 2002). These former studies report isocitrate levels comparable to the present study although the number of animals and samples involved in these studies are much more limited. The traditional procedure based on precipitation and centrifugation is time and material consuming and may thereby restrict the number of analyses. The present direct fluorometric assay is considerably easier to perform. This opens for a markedly higher analytical capacity per day including in-line measurements directly from the herd.

Numerous studies connect variation in isocitrate in dairy milk to FA synthesis during lactation. Garnsworthy et al. (2006) concluded that the variation in milk citrate with stage of lactation is related to de novo synthesis of FA and that the relationship is independent of diet and milk yield. The present study shows that milk citrate and isocitrate are directly proportional to DIM $(P<0.001$; see Table 3$)$, but both inversely proportional to milk yield $(P<0.001)$. The regulation and expression of ICDH in the mammary gland has been studied (Seery and Farrell, 1990; Farrell et al. 1990), as well as in relation to gestation and lactation (Farrell et al., 1987). The $\mathrm{NADP}^{+}$-dependent form (ICDH1) is elevated postpartum where milk FA synthesis starts. In addition, Liu et al. (2006) demonstrated that ICDH1 mRNA levels in bovine mammary tissue increased by 2.3-fold after parturition compared with late pregnancy. Furthermore, studies strongly suggest that long-chain
acyl-CoA inhibit the NADPH-producing ICDH enzyme, whereas short-chain acyl-CoA do not (Farrell et al. 1995). This indicates that the ICDH enzyme activity is depressed when dietary FA are available from the blood, and the depression is abolished or reduced when short-chain FA are produced in the mammary gland by the de novo synthesis.

Basic biochemistry, former studies, and the present study strongly indicate that the presence of isocitrate in milk may reflect the energy situation in the udder. Further studies may elucidate if isocitrate in milk has a potential as indicator of energy status in the dairy cow and elaborate more on the physiological background for its variation in milk.

\section{ACKNOWLEDGMENTS}

This work has been supported by the Danish National Advanced Technology Foundation (Copenhagen, Denmark), Lattec I/S (Hillerød, Denmark), The Milk Levy Fund (Aarhus, Denmark), and the Danish Ministry of Food, Agriculture and Fisheries (Copenhagen, Denmark). Thanks to Kasey M. Moyes (University of Maryland, College Park) for valuable discussions. Jens Clausen and Carsten Berthelsen (Department of Animal Science, Aarhus University) are kindly acknowledged for their skillful technical assistance during the course of the work.

\section{REFERENCES}

Bauman, D. E., R. E. Brown, and C. L. Davis. 1970. Pathways of fatty acid swynthesis and reducing equivalent generation in mammary gland of the rat, sow, and cow. Arch. Biochem. Biophys. 140:237-244.

Bauman, D. E., and J. M. Griinari. 2003. Nutritional regulation of milk fat synthesis. Annu. Rev. Nutr. 23:203-227.

Beutler, H.-O. 1989. D-Isocitrate. Pages 13-19 in Methods of Enzymatic Analysis. 3rd ed. H. U. Bergmeyer, ed. VCH Verlagsgesellschaft mbH, Weinheim, Germany.

Boehringer Mannheim. 1995. Methods of Enzymatic Bioanalysis and Food Analysis. Boehringer Mannheim GmbH, Mannheim, Germany.

Chaiyabutr, N., A. Faulkner, and M. Peaker. 1980. The utilization of glucose for the synthesis of milk components in the fed and starved lactating goat in vivo. Biochem. J. 186:301-308.

Chaiyabutr, N., A. Faulkner, and M. Peaker. 1981. Changes in the concentration of minor constituents of goat's milk during starvation and on refeeding of the lactating animal and their relationship to mammary gland metabolism. Br. J. Nutr. 45:149-157.

Farkye, N. Y. 2003. Indigenous enzymes in milk. Chap. 11.7 in Advanced Dairy Chemistry, vol. 1. Kluwer Academic, Dordecht, the Netherlands.

Farrell, H. M., J. Deeney, K. Tubbs, and R. Walsh. 1987. Role of isocitrate dehydrogenase and other Krebs cycle enzymes in lactating bovine mammary gland. J. Dairy Sci. 70:781-788.

Farrell, H. M., J. T. Deeney, E. K. Hild, and T. F. Kumosinski. 1990. Stopped flow and steady state kinetic studies of the effect of metabolites on the stable form of $\mathrm{NADP}^{+}$:isocitrate dehydrogenase. J. Biol. Chem. 265:17637-17643.

Farrell, H. M., E. D. Wichham, and H. C. Reeves. 1995. Effects of long-chain acyl-coenzyme A's on the activity of the soluble form 
of nicotinamide adenine dinucleotide phosphate-specific isocitrate dehydrogenase from lactating bovine mammary gland. Arch. Biochem. Biophys. 321:199-208.

Faulkner, A. 1980. The presence of cellular metabolites in milk. Biochim. Biophys. Acta 630:141-145.

Faulkner, A., E. Y. Brechany, R. M. Mabon, and H. T. Pollock. 1986. Seasonal changes in the fat composition and concentration of citrate and related metabolites in cow's milk. J. Dairy Res. 53:223227.

Faulkner, A., and J. L. Clapperton. 1981. Changes in the concentration of some minor constituents of milk from cows fed low- or highfat diets. Comp. Biochem. Physiol. 68A:281-283.

Garnsworthy, P. C., L. L. Masson, A. L. Lock, and T. T. Mottram. 2006. Variation of milk citrate with stage of lactation and de novo fatty acid synthesis in dairy cows. J. Dairy Sci. 89:1604-1612.

Grigor, M. R., and P. E. Hartman. 1985. NADP-linked dehydrogenases in secreted milk. J. Dairy Res. 52:501-506.

Gumaa, K. A., A. L. Greenbaum, and P. McLean. 1973. Adaptive changes in satellite systems related to lipogenesis in rat and sheep mammary gland and in adipose tissue. Eur. J. Biochem. 34:188198
Hurtaud, C., S. Lemosquet, and H. Rulquin. 2000. Effect of graded duodenal infusions of glucose on yield and composition of milk from dairy cows. 2. Diets based on grass silage. J. Dairy Sci. 83:2952-2962.

Hurtaud, C., H. Rulquin, and R. Verite. 1998. Effects of graded duodenal infusions of glucose on yield and composition of milk from dairy cows. 1. Diets based on corn silage. J. Dairy Sci. 81:3239-3247.

Liu, W., A. V. Capuco, and D. F. Romagnolo. 2006. Expression of cytosolic $\mathrm{NADP}^{+}$-dependent isocitrate dehydrogenase in bovine mammary epithelium: modulation by regulators of differentiation and metabolic effectors. Exp. Biol. Med. (Maywood) 231:599-610.

Moore, J. H., and W. W. Christie. 1979. Lipid metabolism in the mammary gland of ruminant animals. Prog. Lipid Res. 17:347-395.

Rigout, S., S. Lemosquet, A. Bach, J. W. Blum, and H. Rulquin. 2002. Duodenal infusion of glucose decreases milk fat production in grass silage-fed dairy cows. J. Dairy Sci. 85:2541-2550.

Seery, V. L., and H. M. Farrell. 1990. Spectroscopic evidence for ligand-induced conformational change in $\mathrm{NADP}^{+}$:isocitrate dehydrogenase. J. Biol. Chem. 265:17644-17648. 